CLINICAL STUDY

\title{
Adiponectin levels measured in dried blood spot samples from neonates born small and appropriate for gestational age
}

\author{
A Klamer, K Skogstrand ${ }^{1,2}$, D M Hougaard ${ }^{1}$, B Nørgaard-Petersen ${ }^{1}$, A Juul ${ }^{3}$ and G Greisen \\ Department of Neonatology (section 5021), National University Hospital, University of Copenhagen, Blegdamsvej 9, DK-2100 Copenhagen Ø, Denmark, \\ ${ }^{1}$ Department of Clinical Biochemistry, Statens Serum Institut, DK-2300 Copenhagen S, Denmark, ${ }^{2}$ NANEA at Department of Epidemiology and Social \\ Medicine, Aarhus University, DK-8000 Aarhus C, Denmark and ${ }^{3}$ Department of Growth and Reproduction, National University Hospital, University of \\ Copenhagen, DK-2100 Copenhagen Ø, Denmark \\ (Correspondence should be addressed to A Klamer; Email: anja.klamer@rh.dk)
}

A Klamer and K Skogstrand contributed equally to this work

\begin{abstract}
Objective: Adiponectin levels measured in neonatal dried blood spot samples (DBSS) might be affected by both prematurity and being born small for gestational age (SGA). The aim of the study was to measure adiponectin levels in routinely collected neonatal DBSS taken on day 5 (range 3-12) postnatal from infants.

Design: A retrospective case-control study.

Subjects and methods: One hundred and twenty-two infants: 62 very premature (34 SGA) and 60 mature infants (27 SGA). Adiponectin concentrations were determined in stored neonatal DBSS using a sandwich immunoassay based on flow metric Luminex xMap technology.

Results: Adiponectin was measurable in all samples, and repeated measurements correlated significantly $(r=0.94)$. Adiponectin concentrations were negatively associated with both SGA $(B=-0.283, P=0.04)$ and prematurity $(B=-2.194, P<0.001)$, independently of each other. In the premature but not the mature group, adiponectin levels increased with increasing postnatal age at blood sampling $(B=0.175, P<0.001)$.

Conclusions: Reliable quantification of adiponectin in stored DBSS is feasible and may be used to study large populations of routinely collected samples. Low levels of adiponectin in neonatal DBSS are associated with SGA as well as prematurity. Blood adiponectin levels increase with postnatal age in premature infants, suggesting a rapid yet unexplained metabolic adaptation to premature extrauterine life.
\end{abstract}

European Journal of Endocrinology 157 189-194

\section{Introduction}

During the first weeks of life, newborns face a rapid organ and metabolic adaptation to extrauterine life. Adiponectin may play an important role in this adaptation process due to its involvement in the regulation of insulin sensitivity, and thereby perhaps in early postnatal growth. In adults, adiponectin is involved in the regulation of insulin sensitivity $(1,2)$, and might predict future development of insulin resistance (3). High levels of adiponectin are associated with a reduced risk of developing type II diabetes (4), and adiponectin has an anti-atherogenic effect (5).

Previous studies on adiponectin levels in newborns were mainly performed using cord serum. Cord serum adiponectin concentrations were positively correlated to birth weight (BW) in most (6-10) but not all studies $(11,12)$, and some $(6,7,10,11)$ but not all (9) investigators found a positive correlation between gestational age (GA) and cord serum adiponectin levels.
Newborns had up to three times higher adiponectin levels than their mothers $(9,11)$, and in mature infants these high levels seemed stable during the first week of life $(6,8,13)$.

Dried blood spot samples (DBSS), collected a few days after birth for newborn screening programs and then stored, are blood samples available for studies of pathological peri- and neonatal conditions. Since they are collected from populations with no selection and universal coverage, stored residual DBSS constitute a valuable resource for retrospective studies and epidemiological research. A newly developed multiplex sandwich immunoassay based on flow metric Luminex xMAP technology made it possible to measure multiple protein markers in the small amount of blood available in these samples (14). We have now used this technology to measure adiponectin in neonatal DBSS.

To our knowledge, only two partly contradictory studies have addressed adiponectin levels in small for gestational age (SGA) versus appropriate for gestational 
age (AGA) newborns $(12,15)$. Therefore, we decided to investigate how SGA and prematurity affects adiponectin levels in newborns.

\section{Subjects and methods}

\section{Study population}

We included 122 infants in four groups: 1) premature SGA $(n=34) ; 2)$ premature AGA $(n=28) ; 3)$ mature SGA $(n=27)$; and 4$)$ mature AGA $(n=33$; for details see Table 1). Inclusion criterion for the premature groups was GA below 32 weeks and for the mature groups GA 37-42 weeks. SGA was defined as BW below -2 s.D. for GA, according to the intrauterine growth charts of Marsal et al, (16). The premature infants were admitted to our neonatal intensive care unit at Rigshospitalet in 2004 , and only surviving infants were included. Mature SGA and AGA infants were identified at Statens Serum Institut (SSI) or Rigshospitalet. The infants were matched on birth date to diminish the problem of storage time of the DBSS across the groups, and the premature infants were further matched on GA to make sure these groups were comparable.

\section{Samples}

DBSS from the Danish neonatal screening program were used. According to the sampling instructions, capillary blood from the heel is spotted on filter paper (Schleicher \& Schuell 903) preferably 5-8 days after birth, dried for 2-3 h, and mailed to SSI. After screening analysis, surplus DBSS are stored dry in a refrigerator for approximately a week before final storage at $-24^{\circ} \mathrm{C}$ in the biological specimen bank. To study the stability of adiponectin, blood from ten healthy adult volunteers was spotted on filter paper and left at room temperature

Table 1 Characteristics of the study population.

\begin{tabular}{|c|c|c|c|c|}
\hline & \multicolumn{2}{|c|}{ Premature } & \multicolumn{2}{|c|}{ Mature } \\
\hline & $\begin{array}{c}\text { SGA group } \\
(n=34)\end{array}$ & $\begin{array}{c}\text { AGA group } \\
(n=28)\end{array}$ & $\begin{array}{c}\text { SGA group } \\
(n=27)\end{array}$ & $\begin{array}{c}\text { AGA group } \\
(n=33)\end{array}$ \\
\hline $\begin{array}{l}\text { Adiponectin } \\
(\mu \mathrm{g} / \mathrm{ml})^{\star}\end{array}$ & $6.2 \pm 4.0$ & $8.9 \pm 6.1$ & $12.8 \pm 5.4$ & $14.0 \pm 3.9$ \\
\hline $\begin{array}{l}\text { Gestational } \\
\text { age }^{*} \\
\text { (weeks) }\end{array}$ & $29.0 \pm 1.9$ & $28.6 \pm 2.0$ & $39.9 \pm 1.4$ & $40.4 \pm 1.1$ \\
\hline Gender (M/F) & 23/11 & $19 / 9$ & $19 / 8$ & $16 / 17$ \\
\hline $\begin{array}{l}\text { Birth weight* } \\
\text { (g) }\end{array}$ & $921 \pm 252$ & $1330 \pm 348$ & $2597 \pm 212$ & $3626 \pm 431$ \\
\hline $\begin{array}{l}\text { Birth weight- } \\
\text { SDS }^{*}\end{array}$ & $\begin{array}{c}-3.05 \pm \\
0.70\end{array}$ & $\begin{array}{r}-0.28 \pm \\
0.58\end{array}$ & $\begin{array}{r}-2.29 \pm \\
0.23\end{array}$ & $-0.05 \pm 0.77$ \\
\hline $\begin{array}{l}\text { Postnatal age } \\
\text { at blood } \\
\text { sampling } \\
\text { (days) }^{\star}\end{array}$ & $5.9 \pm 2.0^{\mathrm{a}}$ & $6.8 \pm 2.2$ & $6.2 \pm 2.0^{b}$ & $6.2 \pm 1.9^{c}$ \\
\hline $\begin{array}{l}\text { Mother's age } \\
\text { (years) }\end{array}$ & $30.3 \pm 4.5$ & $31.0 \pm 5.4$ & $32.4 \pm 5.2$ & $29.7 \pm 3.7$ \\
\hline
\end{tabular}

${ }^{*}$ Mean \pm 1 s.D. ${ }^{\mathrm{a}} n=33,{ }^{\mathrm{b}} n=26,{ }^{\mathrm{c}} n=32$. for $0,3,5,7,14$, and 28 days respectively before storage at $-24{ }^{\circ} \mathrm{C}$.

\section{Adiponectin assay}

Adiponectin concentration in DBSS was measured with 14 other cytokines (interleukins $1 \beta, 2,4,6,8$, 10 , and 12, tumor necrosis factors $\alpha$ and $\beta$, neurotrophin-4, C-reactive protein, insulin-like growth factor-binding proteins 1 and 3, and leptin) by a multiplex sandwich immunoassay using Luminex xMAP technology essentially as described by Skogstrand et al. (2005) (14). Due to conflicts of interest and lack of validation of some of the proteins measured, only data on the adiponectin determinations are presented. In short, anti-human adiponectin (Cat. no. MAB1065, R\&D Systems Inc., Minneapolis, MN, USA) was coupled to carboxylated beads (Luminex Corp., Austin, TX, USA) for use as capture antibody. Standard curves for adiponectin were made by spotting recombinant human adiponectin (Cat no. 1065-AP, R\&D Systems) on filter paper models. Two filter paper disks, equivalent of $6 \mu \mathrm{l}$ whole blood, were punched out and extracted in $180 \mu \mathrm{l}$ buffer with protease inhibitor. The assay was subsequently setup for triplicate determinations. The $50 \mu \mathrm{l}$ sample extract was incubated with a suspension of capture antibody-conjugated bead sets, including the antiadiponectin-conjugated set, and the beads were washed as described (14). The captured antigens were reacted with a mixture of biotinylated detection antibodies, including biotinylated anti-human adiponectin (Cat. no. BAM1065, R\&D Systems), and finally incubated with streptavidin-phycoerythrin. The beads were washed, re-suspended, and analyzed on the Luminex 100.

Standard curves were calculated by a five-parameter logistic equation (5PL), and goodness of fit expressed as standards recovery (back calculation of standards). Because of lack of sufficiently concentrated adiponectin, the standard curve was extrapolated by 5PL for readings of high sample concentrations. To evaluate the robustness of this extrapolation, determinations of adiponectin in DBSS from 56 infants in two different runs were compared. Determination of intra-assay coefficients of variance $(\mathrm{CV} \%)$ was done by measuring eight identical samples in the same run and inter-assay $\mathrm{CV} \%$ by measuring four identical samples in the same run repeated for 4 different days. Lower limit of detection (LOD) was defined as the concentration resulting in a response two S.D. away from zero dose response.

\section{Anthropometrical data}

BW, GA, date of blood sampling, and maternal age were obtained from hospital records or from SSI. The GA of some infants in the mature AGA group was given in full weeks, thus making these infants 
younger. To correct for this, the GA was calculated as full weeks plus three days. Three infants lacked date of blood sampling and were excluded from the analysis regarding this variable. In the premature groups, we obtained data on parity $n=53$ (27 SGA), mode of delivery (vaginal versus section) $n=55$ (28 SGA), and nutrition the day before blood sampling $n=39$ (20 SGA) from hospital records. Nutritional intake was calculated from 0600 to $0600 \mathrm{~h}$ the next day. The nutritional value of breast milk was set to $70 \mathrm{kcal} / 100 \mathrm{ml}$ and the content of protein was set to $1.2 \mathrm{~g} / 100 \mathrm{ml}$ regardless of whether it was mother's milk or banked breast milk. The nutritional value of parenteral nutrition and fluids was obtained from the manufacturers.

\section{Ethical considerations}

The local ethics committee (KF (01) 259275 and KF (II) 271665) and the board of the biological specimen bank at SSI approved the study. The DBSS are stored at SSI in accordance with regulations from the Ministry of Health (17).

\section{Statistical analysis}

Square root transformation resulted in an approximate normal distribution, and was used in statistical analyses. A paired samples $t$-test was used to evaluate the correlation between paired data in the validation of the adiponectin assay. Differences between means were assessed by two-tailed $t$-test. Univariate ANOVA was used for individual variables and general linear models were constructed to test for multiple variables. SPSS statistical package version 13 was used (SPSS Inc., Chicago, IL, USA). A $P$ value $<0.05$ was considered significant.

\section{Results}

The standard curve for adiponectin is shown as Fig. 1A. No cross reactivity to any of 14 other recombinant analytes was observed. The standards recovery was 92$144 \%$ (mean 113\%) indicating a good fit of the curves. Intra- and inter-assay $\mathrm{CV} \%$ was 5.9 and 12.2 respectively and the LOD was $0.0156 \mu \mathrm{g} / \mathrm{ml}$. Correlation between adiponectin determinations in 56 neonatal DBSS obtained from two different runs was $r=0.94 \quad(P<0.001$; Fig. 1B), and mean difference between the two runs was $14.6 \%$ which is of the same magnitude as the inter-assay $\mathrm{CV} \%$. The correlation between the two runs is lower at higher concentrations; however, we have very few samples in this area and therefore included them in our analysis. In a future study we might consider diluting the samples. Adiponectin concentrations declined steadily following storage at room temperature, and this decline became significant after 5 days of storage at room temperature. The correlation between adiponectin concentrations at days 1 and 5 was excellent $(r=0.98, P=0.002$; Fig. 1C). Adiponectin in serum was 2.7 times higher than in DBSS (corrected for hematocrit) and determinations from the two media correlated well $(r=0.87$, $P=0.001$; Fig. 1D). Adiponectin levels in the mature AGA group were 2.5 times higher than in the adult group (data not shown).

The mean GA was $28.8 \pm 1.9$ weeks in the premature group and $40.2 \pm 1.2$ weeks in the mature group. Mean BW-SDS was $-2.71 \pm 0.66$ and $-0.15 \pm 0.69$ in the SGA and AGA groups respectively. The mean BW-SDS was lower in the premature than in the mature SGA group $(P<0.0001)$, but did not differ between the AGA groups $(P=0.19$; Table 1$)$. In univariate analysis, prematurity explained $31 \%(r=0.55, P<0.001)$ and SGA explained $6 \%(r=0.24, P<0.008)$ of the variation in adiponectin levels (Fig. 2A-C). Postnatal age at blood sampling was between 3 and 12 days and did not differ significantly between the four groups, hence the collection procedure for the neonatal DBSS was followed even in the two groups of very premature infants. Postnatal age at blood sampling explained $3.9 \%$ of the variation in adiponectin levels $(r=0.20, P=0.032$; Fig. 2D). If the data are extrapolated back to day 0 , the adiponectin level in the mature group was $13.7 \mu \mathrm{g} / \mathrm{ml}$ when compared with $2.3 \mu \mathrm{g} / \mathrm{ml}$ in the premature group (untransformed data). Gender and maternal age did not explain any of the variation in adiponectin levels. In the premature group we had data on parity, mode of delivery, and nutritional intake. Neither parity nor mode of delivery explained any of the variation in adiponectin levels in this group. Mean nutritional intake the day before blood sampling was $86 \pm 31 \mathrm{kcal} / \mathrm{kg}$ in the premature SGA group and $91 \pm 21 \mathrm{kcal} / \mathrm{kg}$ in the premature AGA group $(P=0.57)$ Kcal $/ \mathrm{kg}$ explained $11 \%$ of the variation in adiponectin levels in the premature group $(r=0.34, P=0.035)$. In a general linear model including BW-SDS, GA and $\mathrm{kcal} / \mathrm{kg}$ as continuous variables, the association was weakened however $(P=0.06)$.

A general linear model, including SGA versus AGA and premature versus mature as fixed factors, and postnatal age at blood sampling as a continuous variable, explained $43 \%$ of the variation in adiponectin levels. SGA was an independent predictor of adiponectin levels $(B=-0.283, P=0.04)$ and so was prematurity $(B=-2.194, P<0.001)$. There was a significant interaction between postnatal age at blood sampling and the grouping premature versus mature $(P=0.004)$. In the premature but not the mature group, adiponectin levels were positively associated with an increase in postnatal age (Table 2). In an attempt to explain these findings, the co-variation between age at the day of blood sampling and kcal per kg body weight was tested 
A

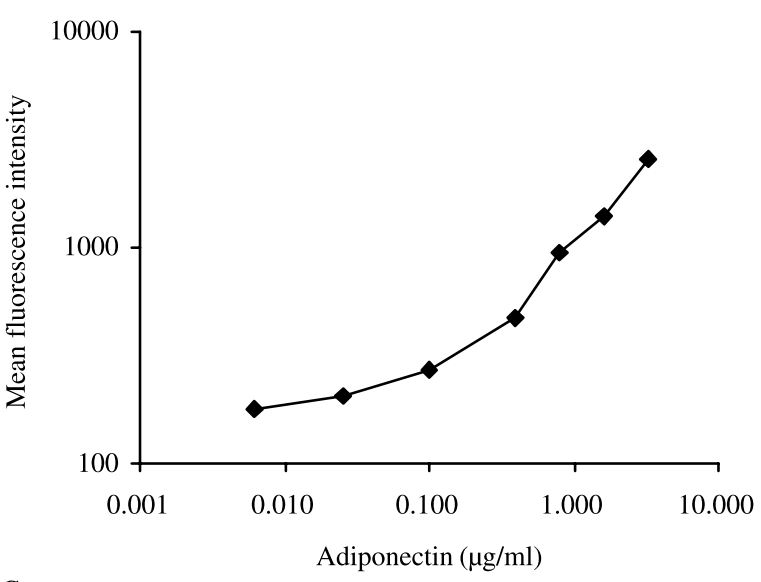

C

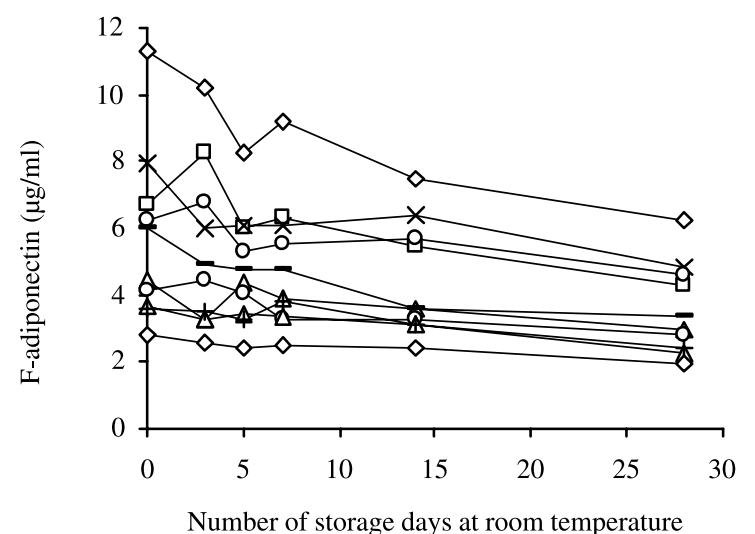

B

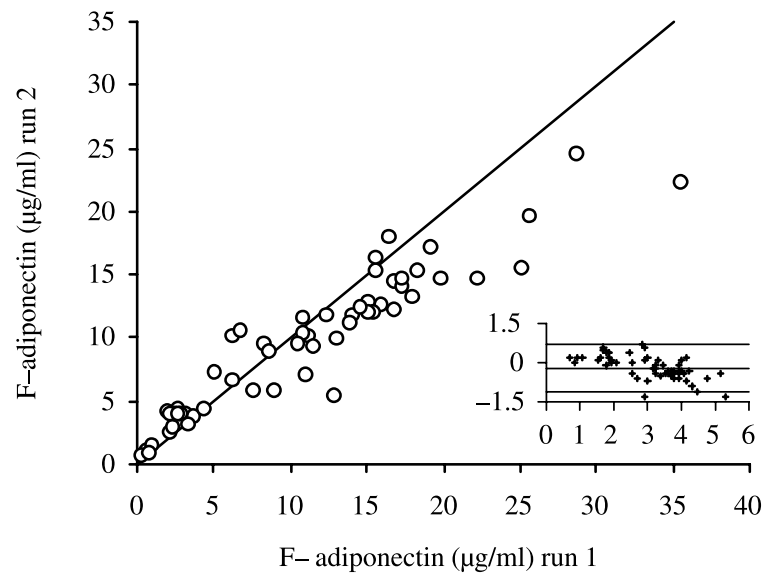

$\mathrm{D}$

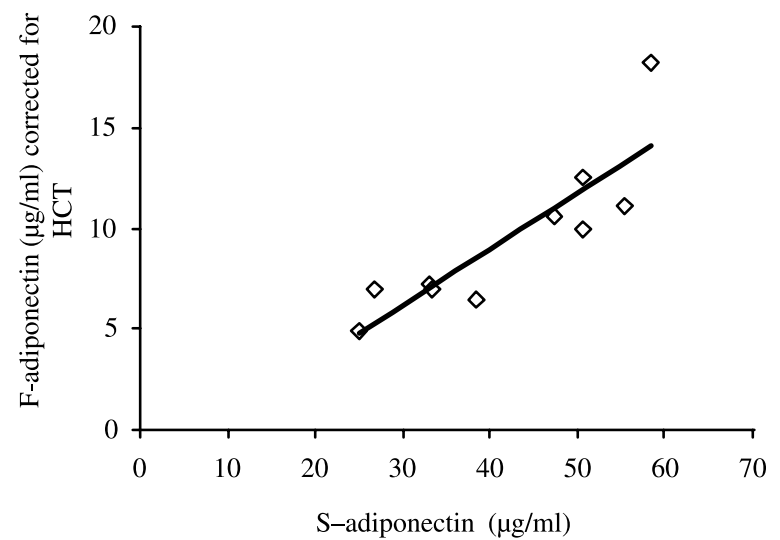

Figure 1 Adiponectin measurements in dried blood spot samples. (A) Standard curve for adiponectin in DBSS (F-adiponectin, concentration of adiponectin in dried blood spot samples). (B) Correlation between repeated measurements of adiponectin DBSS ( $n=56$ ); the solid line is $x=y$; a Bland-Altman plot in square root transformed levels with mean difference \pm 2 s.D. is inserted. (C) Influence of storage at room temperature on adiponectin concentrations in DBSS $(n=10)$. (D) Correlation between adiponectin measured in serum when compared with DBSS.

in the premature group and we found a similar significant positive relation $(r=0.50, P=0.001)$.

\section{Discussion}

Our results show that adiponectin can be reliably measured in stored filter paper (DBSS) and that neonatal levels are negatively associated with both SGA and prematurity, independently of each other.

Measurable adiponectin in DBSS decreased with storage time at room temperature. However, because the infants were matched on birth date, and the neonatal DBSS were collected and handled according to a strict national standardized procedure even in our neonatal intensive care unit, we do not suspect bias between our groups due to collection, mailing, or storage procedures. The correlation between adiponectin levels in DBSS and serum was satisfactory and the adiponectin levels in term AGA newborns was 2.5 times higher than the level found in healthy adults, which is of the same magnitude as found by other investigators $(6,18)$.
In our study, we found a strong negative effect of prematurity as others have done $(6,9,10)$.

For the first time, the correlation between adiponectin levels and BW-SDS is studied in a cohort comprising both premature and mature infants divided in groups of AGA and SGA infants. Our results in the mature groups are in contrast to the findings by Kajantie et al. (12) who did not find a correlation between BW-SDS and adiponectin levels in their mature group; however, their span of BW-SDS was more narrow than ours. Our results are in accordance with the results of Kamoda et al. (15) finding a correlation between adiponectin levels and BW-SDS in premature infants. Therefore, we find it reasonable to suggest that low BW-SDS is associated with low adiponectin levels regardless of GA.

Adiponectin is an interesting cytokine due to its involvement in the regulation of insulin sensitivity in adults. However, the association between adiponectin levels and insulin sensitivity in infancy and childhood is intriguing. In adults, high adiponectin levels were associated with high insulin sensitivity (19). If this were the case in newborns, we would expect the 

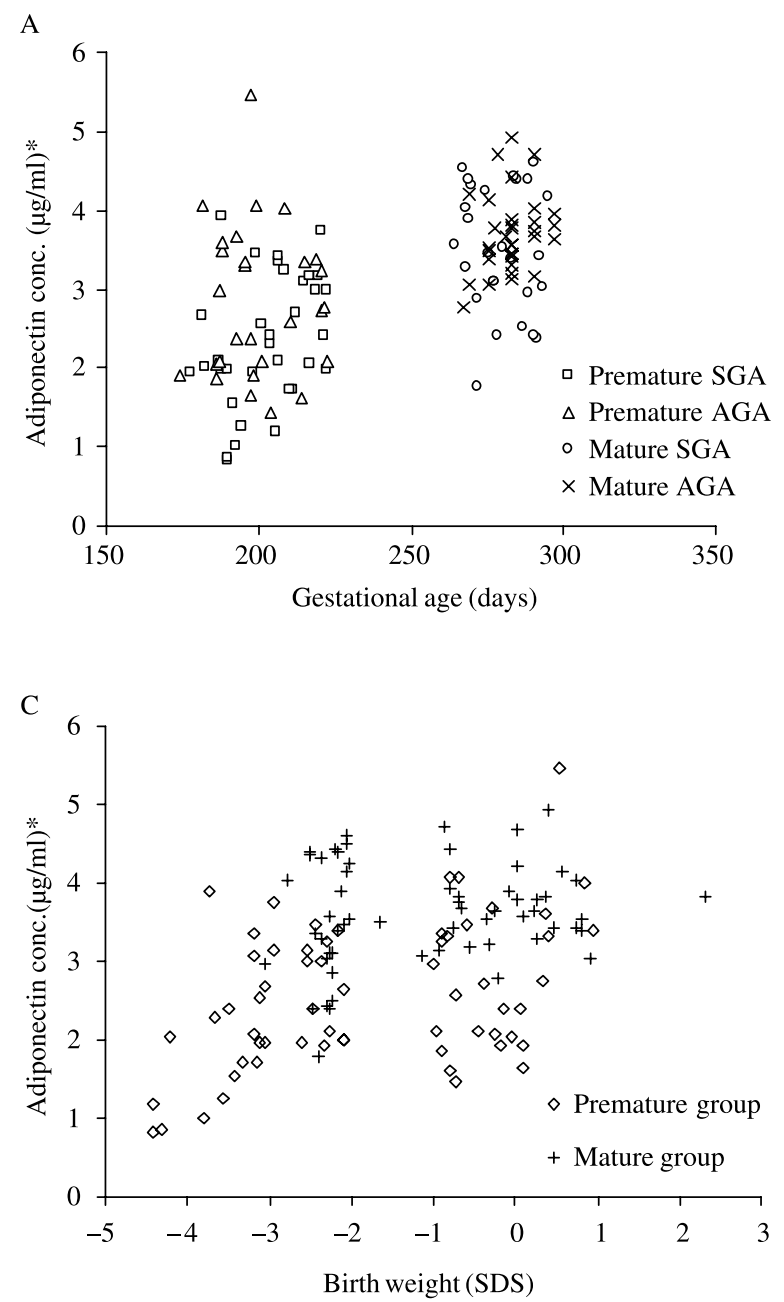

B

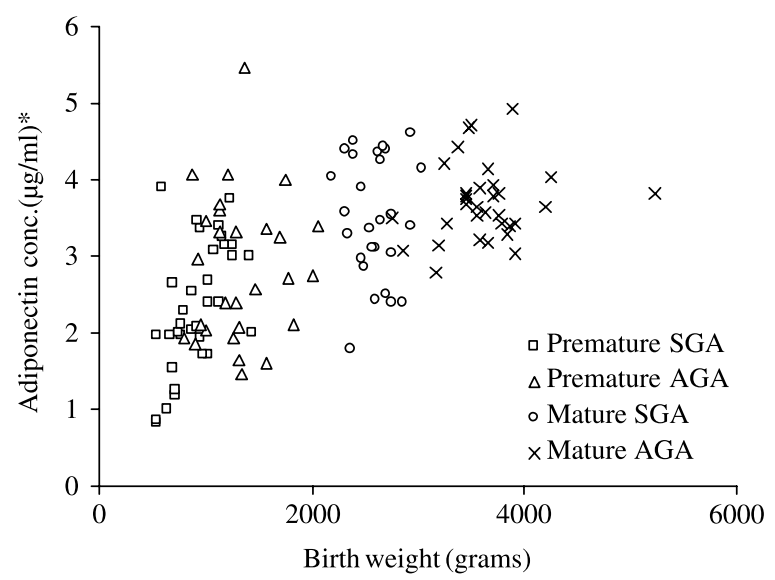

$\mathrm{D}$

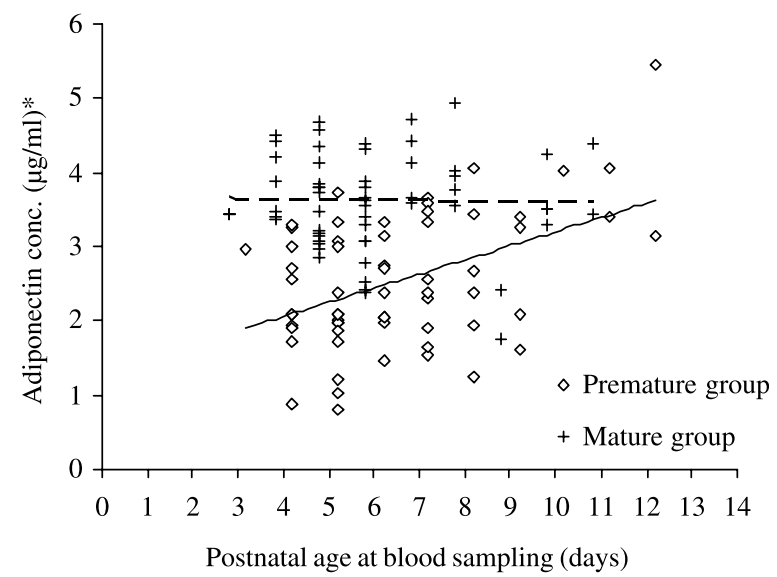

Figure 2 The relation of gestational age, birth weight, and postnatal age at blood sampling to adiponectin levels. (A-C) Variation of GA, BW, and BW-SDS within and among the four groups and their relation to the adiponectin levels. (D) Correlation between adiponectin levels and postnatal age at blood sampling. The solid and the dotted lines are the regression lines for the premature and the mature groups respectively. *Square-root transformed levels.

infants in the SGA and premature groups to be less insulin sensitive than the infants in the AGA and mature groups, who had higher adiponectin levels. In healthy term infants, other investigators found adiponectin levels negatively correlated with insulin levels when controlled for BW, BMI, or BW/BL ratio, which might indicate a positive correlation between adiponectin levels and insulin sensitivity present at birth (6). However, the literature on insulin sensitivity in newborns is conflicting. In a study by Gray et al. newborn SGA infants (day 1-65) showed higher insulin levels $1 \mathrm{~h}$ after an oral milk tolerance test than AGA infants (20). Contrasting this, a study on insulin sensitivity in premature neonates, within 14 days post partum, found no difference between SGA and AGA infants (21) and finally, term SGA newborns, studied $48 \mathrm{~h}$ post partum, were more insulin sensitive than their AGA peers as evaluated by an i.v. glucose tolerance test (22). This indicates that research on insulin sensitivity and adiponectin levels in the newborn is still highly relevant. We only present data on adiponectin and find it interesting that adiponectin levels in newborns are positively correlated to body weight, contrasting with the results in adults, but they are in accordance with the expected low adiponectin levels in a group of infants who are at risk of developing insulin resistance later in life.

In accordance with other studies $(6,8)$, adiponectin levels were high shortly after birth in the mature groups. Interestingly, adiponectin levels increased rapidly with postnatal age in very premature infants. By days 11-12 post partum, the premature infants had adapted to adiponectin levels corresponding to those of mature infants, an increase that takes 10-12 weeks in utero. Kajantie et al. found cord adiponectin levels to be approximately six times higher in their mature infants when compared with their premature infants. 
Table 2 Parameter estimates of square root-transformed adiponectin as dependent variable $(n=119)$.

\begin{tabular}{|c|c|c|c|c|}
\hline Variable & Category & $B$ & $95 \% \mathrm{Cl}$ & $P$ value \\
\hline \multicolumn{5}{|c|}{ Dependent variable: square-root adiponectin } \\
\hline Intercept & & 3.782 & 3.132 to 4.433 & $<0.001$ \\
\hline Gestational age & $\begin{array}{l}\text { Premature group } \\
\text { Mature group }\end{array}$ & $\begin{array}{l}-2.194 \\
\text { Baseline }\end{array}$ & -3.074 to -1.313 & $<0.001$ \\
\hline Birth weight-SDS & $\begin{array}{l}\text { SGA group } \\
\text { AGA group }\end{array}$ & $\begin{array}{l}-0.283 \\
\text { Baseline }\end{array}$ & -0.555 to -0.012 & 0.041 \\
\hline Postnatal age at blood sampling & $\begin{array}{l}\text { Premature group ( } 1 \text { day more) } \\
\text { Mature group ( } 1 \text { day more) }\end{array}$ & $\begin{array}{c}0.175 \\
-0.007\end{array}$ & $\begin{array}{l}0.085 \text { to } 0.265 \\
-0.105 \text { to } 0.092\end{array}$ & $\begin{array}{l}<0.001 \\
0.894\end{array}$ \\
\hline
\end{tabular}

Extrapolating our data back to day 0, our findings are of the same magnitude. The study was too small to find out whether postnatal age, caloric intake or perhaps third factors were responsible for the change in adiponectin levels in premature infants. It is interesting that whereas maturation and preparation for extrauterine life regarding adiponectin is probably gradual during the last trimester (12), apparently it is induced very rapidly after preterm birth. Further studies are needed to address this issue.

\section{Funding}

The Research Council at Rigshospitalet (National University Hospital, University of Copenhagen) and Novo Nordisk A/S supported this study.

\section{References}

1 Staiger $\mathrm{H}$ \& Haring HU. Adipocytokines: fat-derived humoral mediators of metabolic homeostasis. Experimental and Clinical Endocrinology and Diabetes 2005113 67-79.

2 Weyer C, Funahashi T, Tanaka S, Hotta K, Matsuzawa Y, Pratley RE \& Tataranni PA. Hypoadiponectinemia in obesity and type 2 diabetes: close association with insulin resistance and hyperinsulinemia. Journal of Clinical Endocrinology and Metabolism 200186 1930-1935.

3 Yamamoto Y, Hirose H, Saito I, Nishikai K \& Saruta T. Adiponectin, an adipocyte-derived protein, predicts future insulin resistance: two-year follow-up study in Japanese population. Journal of Clinical Endocrinology and Metabolism 200489 87-90.

4 Spranger J, Kroke A, Mohlig M, Bergmann MM, Ristow M, Boeing $\mathrm{H} \&$ Pfeiffer AFH. Adiponectin and protection against type 2 diabetes mellitus. Lancet $2003361226-228$.

5 Chandran M, Phillips SA, Ciaraldi T \& Henry RR. Adiponectin: more than just another fat cell hormone? Diabetes Care 200326 2442-2450.

6 Kotani Y, Yokota I, Kitamura S, Matsuda J, Naito E \& Kuroda Y. Plasma adiponectin levels in newborns are higher than those in adults and positively correlated with birth weight. Clinical Endocrinology 200461 418-423.

7 Tsai PJ, Yu CH, Hsu SP, Lee YH, Chiou CH, Hsu YW, Ho SC \& $\mathrm{Chu} \mathrm{CH}$. Cord plasma concentrations of adiponectin and leptin in healthy term neonates: positive correlation with birthweight and neonatal adiposity. Clinical Endocrinology 200461 88-93.

8 Sivan E, Mazaki-Tovi S, Pariente C, Efraty Y, Schiff E, Hemi R \& Kanety H. Adiponectin in human cord blood: relation to fetal birth weight and gender. Journal of Clinical Endocrinology and Metabolism $2003885656-5660$.
9 Chan TF, Yuan SS, Chen HS, Guu CF, Wu LC, Yeh YT, Chung YF, Jong SB \& Su JH. Correlations between umbilical and maternal serum adiponectin levels and neonatal birthweights. Acta Obstetrica et Gynecologica Scandinavica 200483 165-169.

10 Pardo IM, Geloneze B, Tambascia MA \& Barros-Filho AA. Hyperadiponectinemia in newborns: relationship with leptin levels and birth weight. Obesity Research 200412 521-524.

11 Corbetta S, Bulfamante G, Cortelazzi D, Barresi V, Cetin I, Mantovani G, Bondioni S, Beck-Peccoz P \& Spada A. Adiponectin expression in human fetal tissues during mid- and late gestation. Journal of Clinical Endocrinology and Metabolism 2005 90 2397-2402.

12 Kajantie E, Hytinantti T, Hovi P \& Andersson S. Cord plasma adiponectin: a 20-fold rise between 24 weeks gestation and term. Journal of Clinical Endocrinology and Metabolism 200489 4031-4036.

13 Petridou E, Mantzoros CS, Belechri M, Skalkidou A, Dessypris N, Papathoma E, Salvanos H, Lee JH, Kedikoglou S, Chrousos G \& Trichopoulos D. Neonatal leptin levels are strongly associated with female gender, birth length, IGF-I levels and formula feeding. Clinical Endocrinology 200562 366-371.

14 Skogstrand K, Thorsen P, Norgaard-Pedersen B, Schendel DE, Sorensen LC \& Hougaard DM. Simultaneous measurement of 25 inflammatory markers and neurotrophins in neonatal dried blood spots by immunoassay with xMAP technology. Clinical Chemistry 200551 1854-1866.

15 Kamoda T, Saitoh H, Saito M, Sugiura M \& Matsui A. Serum adiponectin concentrations in newborn infants in early postnatal life. Pediatric Research 200456 690-693.

16 Marsal K, Persson PH, Larsen T, Lilja H, Selbing A \& Sultan B. Intrauterine growth curves based on ultrasonically estimated foetal weights. Acta Paediatrica 199685 843-848.

17 Norgaard-Pedersen B \& Simonsen H. Biological specimen banks in neonatal screening. Acta Paediatrica. Supplement 199988 106-109.

18 Lindsay RS, Walker JD, Havel PJ, Hamilton BA, Calder AA \& Johnstone FD. Adiponectin is present in cord blood but is unrelated to birth weight. Diabetes Care 200326 2244-2249.

19 Matsubara M, Katayose S \& Maruoka S. Decreased plasma adiponectin concentrations in nondiabetic women with elevated homeostasis model assessment ratios. European Journal of Endocrinology 2003148 343-350.

20 Gray IP, Cooper PA, Cory BJ, Toman M \& Crowther NJ. The intrauterine environment is a strong determinant of glucose tolerance during the neonatal period, even in prematurity. Journal of Clinical Endocrinology and Metabolism 2002 87 4252-4256.

21 Leipala JA, Raivio KO, Sarnesto A, Panteleon A \& Fellman V. Intrauterine growth restriction and postnatal steroid treatment effects on insulin sensitivity in preterm neonates. Journal of Pediatrics $2002141472-476$.

22 Bazaes RA, Salazar TE, Pittaluga E, Pena V, Alegria A, Iniguez G, Ong KK, Dunger DB \& Mericq MV. Glucose and lipid metabolism in small for gestational age infants at $48 \mathrm{~h}$ of age. Pediatrics 2003 $111804-809$.

Received 28 November 2006

Accepted 10 May 2007 